\title{
The current role of sublingual immunotherapy in the treatment of allergic rhinitis in adults and children
}

This article was published in the following Dove Press journal:

Journal of Asthma and Allergy

18 February 2011

Number of times this article has been viewed

\author{
Cristoforo Incorvaia' \\ Simonetta Masieri ${ }^{2}$ \\ Silvia Scurati ${ }^{3}$ \\ Silvia Soffia ${ }^{3}$ \\ Paola Puccinelli ${ }^{3}$ \\ Franco Frati $^{3}$ \\ 'Allergy/Pulmonary rehabilitation, \\ Istituti Clinici di Perfezionamento, \\ Milan, Italy; ${ }^{2}$ ENT Clinic, University \\ La Sapienza, Rome, Italy; ${ }^{3}$ Medical and \\ Scientific Department, Stallergenes, \\ Milan, Italy
}

\begin{abstract}
Allergic rhinitis is a very common disease affecting about $20 \%$ of people. It may be treated by allergen avoidance when possible, by antiallergic drugs such as antihistamines and topical corticosteroids, and by allergen-specific immunotherapy. The latter is the only treatment able to act on the causes and not only on the symptoms of respiratory allergy and is able to maintain its efficacy even after stopping, provided an adequate duration of treatment of 3-5 years is ensured. Sublingual immunotherapy (SLIT) was introduced in the $1990 \mathrm{~s}$ as a possible solution to the problem of adverse systemic reactions to subcutaneous immunotherapy and has been demonstrated by more than 50 trials and globally evaluated thus far by five metaanalyses as an effective and safe treatment for allergic rhinitis. Life-threatening reactions are extremely rare. However, it is important to note that clinical efficacy occurs only if SLIT meets its needs, ie, sufficiently high doses are regularly administered for at least 3 consecutive years. This is often overlooked in the current practice and may prevent the same success reported by trials from being achieved.
\end{abstract}

Keywords: allergic rhinitis, sublingual immunotherapy, efficacy, safety, compliance, meta-analysis

\section{Introduction}

Allergic rhinitis (AR) is a very common disease with a high and still increasing world prevalence. ${ }^{1}$ AR causes an important medical and social burden, ${ }^{2}$ which further increases when the disease is associated with allergic asthma. ${ }^{3}$ In fact, the concurrence of AR and asthma requires more doctor visits and more drugs and worsens patients' quality of life. ${ }^{4}$

The management of respiratory allergy relies on, when possible, allergen avoidance, drug treatment, and allergen-specific immunotherapy (SIT). ${ }^{3}$ SIT is the practice of administering gradually increasing doses of the specific causative allergen to reduce the clinical reactivity of allergic subjects. This treatment has pivotal importance because of its ability to modify the natural history of the disease and to extend its effectiveness after treatment withdrawal, provided it is administered with sufficiently hgh doses and for an adequate duration. ${ }^{5}$ Subcutaneous immunotherapy (SCIT) has for decades been the traditional technique of administration, but it is flawed by the problem of adverse systemic reactions, which, when they are of an anaphylactic type, may be severe and, though very rarely, even fatal. ${ }^{6}$ In recent years, sublingual immunotherapy (SLIT) has emerged as an actual treatment option because of its clinical efficacy and safety. ${ }^{7}$

The first studies on SLIT used low allergen dosages, ${ }^{8,9}$ but it soon became apparent that doses much higher than those administered by SCIT were needed to expect clinical
Correspondence: Cristoforo Incorvaia Allergy/Pulmonary rehabilitation, Istituti Clinici di Perfezionamento, via Bignami I, 20126 Milan, Italy

Tel +390257993289

Fax +39025 7993315

Email cristoforo.incorvaia@gmail.com 
efficacy. In consensus documents, an optimal dose as high as at least 50 times the dose administered by injection was suggested. ${ }^{3}$ The high number of trials on SLIT conducted in recent years allows an accurate evidence-based assessment of its efficacy based on several meta-analyses, and the most recent data also give an indication on optimal doses to be used.

This review aims to analyze the current role of SLIT in the treatment of AR using evidence-based demonstrations of its efficacy and safety.

\section{Search strategy and study selection}

The medical literature was searched by means of the MedLine database for the years 1990-2010 using the following key words: "sublingual immunotherapy", "efficacy", "safety", "tolerability", "compliance", "meta-analysis", and "systematic review". The search was augmented by scanning the references cited in the articles identified. Only full-length articles in English that had been published in referenced journals were considered. Full copies of the articles were retrieved for analysis and the relevant data were extracted.

\section{Analysis of efficacy of SLIT}

The clinical efficacy of SLIT in AR, as for SIT in general, can be evaluated by a decrease in symptom scores of rhinitis and in the use of symptomatic drugs. Most of the placebocontrolled studies usually include small patient populations and thus are exposed to the issue of not having fully reliable statistical significance. An adequate statistical method to achieve statistical reliability is meta-analysis that estimates more powerfully the effect size of a medical treatment by combining the results of several trials and expresses the results as standardized mean difference (SMD), comparing the effect of active and placebo treatment on patients. The results from the meta-analyses on SLIT in AR are summarized in Table 1.

In 2005, when 22 randomized controlled trials (RCTs) were available, Wilson et al published the first meta-analysis on SLIT, ${ }^{10}$ which demonstrated a significantly higher efficacy of SLIT versus placebo, with an SMD corresponding to -0.42 for symptom scores $(P=0.002)$ and to -0.43 for medication scores $(P=0.00003)$. In the same year, another meta-analysis dealt with seven RCTs conducted on children aged up to 14 years and found that SLIT was significantly effective on asthma symptoms (SMD -1.42; $P=0.01)$ and on drug consumption (SMD $-1.01 ; P=0.06$ ), but the improvement did not reach significance for nasal and eye symptoms. ${ }^{11}$

However, a further meta-analysis on SLIT in children, concerning only efficacy on AR, showed positive results. ${ }^{12}$ Ten RCTs with an overall number of 484 patients (245 actively treated and 239 placebo treated) were included, and a significant reduction of both symptoms (SMD -0.56, $P=0.02$ ) and medication scores (SMD -0.76, $P=0.03$ ) was found. Of note, the subanalysis addressing the length of treatment and the kind of allergen administered demonstrated a higher efficacy for durations longer than 18 months and for pollen allergens compared with house dust mites.

The most recent meta-analyses highlighted the results according to the allergen used for SLIT. Compalati et al examined eight RCTs for AR (including 194 adults and children). ${ }^{13}$ A significant reduction in symptoms of $\mathrm{AR}$ (SMD -0.95; $P=0.02$ ) and a significant decrease in antiallergic medication use (SMD - $1.88 ; P=0.04)$ in SLIT-treated patients compared with placebo was found. Di Bona et al performed a meta-analysis on RCTs conducted with grass pollen extracts, concluding that SLIT significantly reduces both symptoms (SMD -0.32) and medication use (SMD -0.33) compared with placebo, that it is more efficacious in adults than in children, and that prolonging the duration of preseasonal treatment for more than 12 weeks improves treatment efficacy. ${ }^{14}$

A recognized limit of meta-analysis is the usually relevant heterogeneity of the included studies, due to the different dosages, standardization methods, treatment schedules, and patient populations. Recent evaluations considered the available meta-analyses altogether but reached contrasting conclusions. Nieto et al checked the data reported in the

Table I Summary results from meta-analyses on sublingual immunotherapy in allergic rhinitis

\begin{tabular}{|c|c|c|c|c|}
\hline Study & Population & Number of patients & Allergen used & $\begin{array}{l}\text { Standardized } \\
\text { mean difference }\end{array}$ \\
\hline Wilson et al $^{10}$ & Adults and children & 979 (503 active, 476 placebo) & Various & -0.42 \\
\hline Olaguibel et al"' & Children & 256 (I29 active, I 27 placebo) & Various & -0.44 \\
\hline Penagos et $\mathrm{al}^{12}$ & Children & 484 (245 active, 239 placebo) & Various & -0.56 \\
\hline Compalati et $\mathrm{al}^{13}$ & Adults and children & 382 (194 active, 188 placebo) & House dust mite & -0.95 \\
\hline Di Bona et $\mathrm{al}^{14}$ & Adults and children & 297 ( 1518 active, 1453 placebo) & Grass pollen & -0.32 \\
\hline
\end{tabular}


original studies and concluded that the meta-analyses show "discrepancies, inconsistencies, and lack of robustness" and "do not provide enough evidence" for the current routine use of SLIT in patients with allergic asthma or rhinoconjunctivitis. ${ }^{15}$ By contrast, the overall evaluation of all meta-analyses (five on SLIT and two on SCIT) by Compalati et al, despite a significant heterogeneity of studies and one negative meta-analysis, led the authors to conclude that "SIT can be recommended for the treatment of respiratory allergy because of its efficacy in reducing asthma and rhinitis symptoms". ${ }^{16}$

The limit of heterogeneity can be overcome by analyzing single studies conducted on large numbers of patients that allow adequate statistical power. The recent preparations for SLIT in tablets of grass pollen extract were evaluated on large populations, including 855 adults treated by a Timothy grass extract, ${ }^{17} 628$ adults treated using a five-grass pollen extract, ${ }^{18}$ and 278 children treated using the same five-grass preparation. ${ }^{19}$ These studies showed a highly significant improvement in symptoms and rescue medication scores in actively treated compared with placebo-treated patients during the grass pollen season.

Important observations from such studies concern the dose dependence of clinical efficacy: only high doses, corresponding to $75,000 \mathrm{SQ}$ in the trial with the Timothy grass pollen ${ }^{17}$ and to 300 IR in the trial with the five-grass extract, ${ }^{18}$ were effective. These doses correspond to $15 \mathrm{mcg}$ and $20 \mathrm{mcg}$ of the major allergens $\mathrm{Phl} \mathrm{p} \mathrm{5,} \mathrm{respectively.}$ Calculating the monthly cumulative dose, the World Allergy Organization Position Paper on SLIT suggested the monthly dose of $600 \mathrm{mcg}$ of the grass pollen major allergen Phl p 5 as being optimal. ${ }^{20}$ This is confirmed by the meta-analysis on grass pollen SLIT by Di Bona et al, showing clearly better results (SMD -0.47) in patients receiving monthly doses of 275-600 mcg than in patients receiving monthly doses lower than $275 \mathrm{mcg}$ (SMD -0.16). ${ }^{14}$

Another important aspect of SLIT efficacy is the identification of patients more prone to respond to the treatment. Devillier et $\mathrm{al}^{21}$ performed a post hoc analysis of data from the registrative studies with the new grass pollen tablets for SLIT. ${ }^{18,19}$ From such analysis it was apparent that the magnitude of efficacy was higher in patients with more severe symptoms during the grass pollen season. In fact, for the adult trial, the differences of the symptom-medication score in the active versus placebo groups were $15 \%, 26 \%$, and $37 \%$ for the low-, moderate-, and high-severity tertiles, respectively; in the pediatric trial, these values were $10 \%, 33 \%$, and $34 \%$, respectively. ${ }^{21}$

\section{Analysis of safety and tolerability of SLIT}

The meta-analyses including, along with efficacy, the safety and tolerability aspects of SLIT found that the most common adverse events were local reactions in the oropharynx followed by gastrointestinal reactions (such as vomiting and diarrhea) and that systemic reactions such as asthma, rhinitis, or urticaria were quite rare. ${ }^{10,13}$

Specific reviews on safety are also available that address only children ${ }^{22,23}$ or patients of any age. ${ }^{24,25}$ Of note, differently from SCIT, there was not a dose dependence of safety, as the rate of systemic reactions was similar in studies using low doses and in studies using high doses. ${ }^{24}$ In a subsequent trial evaluating seven groups of patients treated with increasing doses, the treatment-related adverse events, including irritation of the throat, and itching sensations in the mouth and ears, increased with dose. ${ }^{26}$ In fact, local reactions are generally estimated to concern $20 \%-40 \%$ of patients, but they can be easily managed and usually do not result in treatment withdrawal. ${ }^{27}$ Anaphylactic reactions are extremely rare; a review of published reports showed that in most cases the reaction is associated with mistakes, such as the use of an improper mix of allergens or the consumption of very high allergen doses. ${ }^{28}$ However, an increased risk is apparent in subjects undergoing SLIT because of previous systemic reactions to SCIT, ${ }^{29,30}$ especially when no updosing regimens are used. This warrants reconsideration of systemic reactions to SCIT as an admission criterion to SLIT. ${ }^{31}$ In any case, starting directly with the maintenance dose is not recommended in any patient, regardless of previous reactions to IT. In fact, a Phase I study comparing different doses and different updosing or no updosing regimens showed that only the group of patients treated with the highest dose with no updosing had severe local reactions with swelling of throat. ${ }^{32}$

\section{Analysis of compliance with SLIT}

Based on the available studies, the major cause of noncompliance with SLIT is inconvenience due to visits to allergists' offices for the injections. ${ }^{33}$ SLIT has different compliance issues from SCIT, because it is administered at home by patients themselves, and thus should have compliance problems similar to drug treatment. However, the findings from studies specifically designed for compliance and adherence indicate quite satisfactory results, with values between $75 \%$ and $95 \%$ of treated subjects. ${ }^{33}$ In a survey on allergists' opinions on the factors positively influencing adherence to SLIT, the issues judged to be most important were the patient's perception of efficacy, reimbursability, 
and tolerability and the patient's education. ${ }^{34}$ Concerning perception of efficacy, as previously noted in SCIT studies, it was observed that a lack of compliance to SLIT may be caused by the erroneous perception that once allergic symptoms are improved, SLIT is no longer needed. ${ }^{35}$ However, this aspect also belongs to the field of patient education, which has pivotal importance, as shown in a recent study that found a clear difference in compliance between patients receiving a complete educational course on SLIT and those receiving only standard instructions. ${ }^{36}$

\section{Analysis of the carryover effect of SLIT}

A major advantage of SCIT over drug treatment is that efficacy on allergic symptoms persists after its discontinuation. ${ }^{5}$ Recent studies showed that SLIT also has such a carryover effect. In a survey on SLIT using a dust mite extract, 137 patients were divided into two groups, 67 receiving SLIT for 2 years and 70 receiving SLIT for 3 years. All patients were followed up for 3 years after stopping the treatment. A greater improvement of symptoms was found in the patients treated for 3 years. ${ }^{37}$ In a prospective open controlled study, patients monosensitized to mites were divided into four groups, one receiving only drug treatment and the other three receiving SLIT for 3, 4, or 5 years. The observation period reached 15 years, and the clinical scores showed that the benefit persisted for 7 years in patients treated for 3 years, whereas the benefit persisted for 8 years in those treated for $4-5$ years. ${ }^{38}$ Moreover, new allergen sensitizations occurred in all patients treated only with drugs and in less than $25 \%$ of patients receiving SLIT.

\section{Conclusion}

SLIT has gained ample evidence of efficacy and safety and in some European countries is currently used more frequently than SCIT. Apart from its better safety profile, the advantages of SLIT over SCIT are with regard to compliance, which is higher because SLIT does not need to be administered in a medical setting, and cost-effectiveness, because the cost of the injections is not involved. ${ }^{39}$ However, it is important to note that such favorable outcomes exist only if SLIT meets its needs, ie, the administration of high doses is continued regularly for at least 3 consecutive years. In fact, SLIT efficacy is dose dependent, and a sufficient duration of treatment is necessary to induce the immunologic changes underlying clinical effectiveness. Recent studies showed that the mechanism of action of SLIT is similar to that demonstrated for SCIT, ${ }^{40}$ and that when high doses are administered, immunoglobulin
G-blocking antibodies, which were not found in SLIT studies employing low doses, are produced in significant amounts and persist after the discontinuation of treatment. ${ }^{41}$

\section{Disclosure}

Cristoforo Incorvaia is a scientific consultant for Stallergenes, Milan, Italy. The other authors report no conflicts of interest in this work.

\section{References}

1. Asher MI, Montfort S, Björkstén B, et al; ISAAC Phase Three Study Group. Worldwide time trends in the prevalence of symptoms of asthma, allergic rhinoconjunctivitis, and eczema in childhood: ISAAC phases one and three repeat multicountry cross-sectional surveys. Lancet. 2006; 368:733-743.

2. Canonica GW, Bousquet J, Mullol J, et al. A survey of the burden of allergic rhinitis in Europe. Allergy. 2007;62:17-25.

3. Bousquet J, van Cauwenberge P, editors. Allergic rhinitis and its impact on asthma. J Allergy Clin Immunol. 2001;108(Suppl. 5):147-334.

4. Harmsen L, Nolte H, Backer V. The effect of generalist and specialist care on quality of life in asthma patients with and without allergic rhinitis. Int Arch Allergy Immunol. 2010;152:288-294.

5. Bousquet J, Lockey R, Malling HJ, editors. Allergen immunotherapy: therapeutic vaccines for allergic diseases. A WHO Position Paper. J Allergy Clin Immunol. 1998;102:58-62.

6. Lockey RF, Benedikt LM, Turkeltaub PC, et al. Fatalities from immunotherapy (IT) and skin testing (ST). J Allergy Clin Immunol. 1987; 79:660-677.

7. Canonica GW, Passalacqua G. Noninjection routes for immunotherapy. J Allergy Clin Immunol. 2003;111:437-448.

8. Scadding GK, Brostoff J. Low dose sublingual therapy in patients with allergic rhinitis due to house dust mite. Clin Allergy. 1986; $16: 483-491$.

9. Tari MG, Mancino M, Monti G. Efficacy of sublingual immunotherapy in patients with rhinitis and asthma due to house dust mite: a doubleblind study. Allergol Immunopathol. 1990;18:277-284.

10. Wilson DR, Torres-Lima M, Durham S. Sublingual immunotherapy for allergic rhinitis: systematic review and meta-analysis. Allergy. 2005; 60:4-12.

11. Olaguibel JM, Alvarez Puebla MJ. Efficacy of sublingual allergen vaccination for respiratory allergy in children: conclusions from one meta-analysis. J Investig Allergol Clin Immunol. 2005;15:9-16.

12. Penagos M, Compalati E, Tarantini F, et al. Efficacy of sublingual immunotherapy in the treatment of allergic rhinitis in pediatric patients 3-18 years of age: a meta analysis of randomized placebo-controlled, double blind trials. Ann Allergy Asthma Immunol. 2006;97:141-148.

13. Compalati E, Passalacqua G, Bonini M, Canonica GW. The efficacy of sublingual immunotherapy for house dust mites respiratory allergy: results of a GA2LEN meta-analysis. Allergy. 2009;64:1570-1579.

14. Di Bona D, Plaia A, Scafidi V, et al. Efficacy of sublingual immunotherapy with grass allergens for seasonal allergic rhinitis: a systematic review and meta-analysis. J Allergy Clin Immunol. 2010;126:558-566.

15. Nieto A, Mazon A, Pamies R, et al. Sublingual immunotherapy for allergic respiratory diseases: an evaluation of meta-analyses. J Allergy Clin Immunol. 2009;124:157-161.

16. Compalati E, Penagos M, Tarantini D, et al. Specific immunotherapy for respiratory allergy: state of the art according to current meta-analyses. Ann Allergy Asthma Immunol. 2009;102:22-28.

17. Durham SR, Yang WH, Pedersen MR, et al. Sublingual immunotherapy with once daily grass allergen tablet: a randomized controlled trial in seasonal allergic rhinoconjunctivitis. J Allergy Clin Immunol. 2006; 117:802-809. 
18. Didier A, Malling HJ, Worm M, et al. Optimal dose, efficacy, and safety of once daily sublingual immunotherapy with a 5-grass pollen tablet for seasonal allergic rhinitis. J Allergy Clin Immunol. 2007; 120:1338-1345.

19. Wahn U, Tabar A, Kuna P, et al; SLIT Study Group. Efficacy and safety of 5-grass pollen sublingual immunotherapy tablets in pediatric allergic rhinoconjunctivitis. J Allergy Clin Immunol. 2009;123:160-166.

20. Canonica GW, Bousquet J, Casale T, et al. Sublingual immunotherapy: World Allergy Organization Position Paper 2009. Allergy. 2009; 64(Suppl 91):1-59.

21. Devillier P, Brehler R, Sastre J, et al. The clinical development of specific immunotherapies: specific methodological issues and clinical interpretation of results. Allergy. 2010;65(Suppl 92):567.

22. Andrè C, Vatrinet C, Galvain S. Safety of sublingual swallow immunotherapy in children and adults. Int Arch Allergy Immunol. 2000; 121:220-234.

23. Rienzo VD, Minelli M, Musarra A, et al. Post-marketing survey on the safety of sublingual immunotherapy in children below the age of 5 years. Clin Exp Allergy. 2005;35:560-564.

24. Gidaro GB, Marcucci F, Sensi L, et al. The safety of sublingual-swallow immunotherapy: an analysis of published studies. Clin Exp Allergy. 2005;35:565-571.

25. Passalacqua G, Guerra L, Compalati E, Canonica GW. The safety of allergen specific sublingual immunotherapy. Curr Drug Saf. 2007; 2:117-123.

26. Kleine-Tebbe J, Ribel M, Herold DA. Safety of a SQ-standardised grass allergen tablet for sublingual immunotherapy: a randomized, placebo-controlled trial. Allergy. 2006;61:181-184.

27. Frati F, Sensi L, di Rienzo V, et al. A model for management of sublingual immunotherapy. Eur Ann Allergy Clin Immunol. 2003; 35:56-60.

28. André C, Fadel R. Anaphylaxis caused by allergen sublingual immunotherapy? Allergy. 2007;62:1220-1221.

29. De Groot H, Bijl A. Anaphylactic reaction after the first dose of sublingual immunotherapy with grass pollen tablet. Allergy. 2009;64:963-964.
30. Cochard MM, Eigenmann PA. Sublingual immunotherapy is not always a safe alternative to subcutaneous immunotherapy. J Allergy Clin Immunol. 2009;124:378-379.

31. Incorvaia $\mathrm{C}$, Mauro $\mathrm{M}$. Do indications to sublingual immunotherapy need to be revised? J Allergy Clin Immunol. 2010;125:277-278.

32. Larsen TH, Poulsen LK, Melac M, et al. Safety and tolerability of grass pollen tablets in sublingual immunotherapy: a phase 1 study. Allergy. 2006;61:1173-1176.

33. Incorvaia $\mathrm{C}$, Mauro $\mathrm{M}$, Ridolo $\mathrm{E}$, et al. Patient's compliance with allergen immunotherapy. Patient Prefer Adherence. 2008;2:247-251.

34. Passalacqua G, Frati F, Puccinelli P, et al. Adherence to sublingual immunotherapy: the allergist's viewpoint. Allergy. 2009;64:1796-1797.

35. Novembre E, Galli E, Landi F, et al. Coseasonal sublingual immunotherapy reduces the development of asthma in children with allergic rhinoconjunctivitis. J Allergy Clin Immunol. 2004;114:851-857.

36. Incorvaia $\mathrm{C}$, Rapetti $\mathrm{A}$, Scurati $\mathrm{S}$, et al. Importance of patient's education in favouring compliance with sublingual immunotherapy. Allergy. 2010;65:1341-1342

37. Tahamiler R, Saritzali G, Canakcioglu S. Long-term efficacy of sublingual immunotherapy in patients with perennial rhinitis. Laryngoscope. 2007;117:965-969.

38. Marogna M, Spadolini I, Massolo A, et al. Long-lasting effects of sublingual immunotherapy accordino to its duration: a 15-year prospective study. J Allergy Clin Immunol. 2010;126:969-975.

39. Berto P, Frati F, Incorvaia C. Economic studies of immunotherapy: a review. Curr Opin Allergy Clin Immunol. 2008;8:585-589.

40. Incorvaia C, Frati F, Puccinelli P, et al. Effects of sublingual immunotherapy on allergic inflammation. Inflamm Allergy Drug Targets. 2008; 7:167-172.

41. Durham SR, Emminger W, Kapp A, et al. Long-term clinical efficacy in grass-pollen induced rhinoconjunctivitis after treatment with SQ-standardized grass allergy immunotherapy tablet. J Allergy Clin Immunol. 2010;125:131-138.
Journal of Asthma and Allergy

\section{Publish your work in this journal}

The Journal of Asthma and Allergy is an international, peer-reviewed open-access journal publishing original research, reports, editorials and commentaries on the following topics: Asthma; Pulmonary physiology; Asthma related clinical health; Clinical immunology and the immunological basis of disease; Pharmacological interventions and

\section{Dovepress}

new therapies. Issues of patient safety and quality of care will also be considered. The manuscript management system is completely online and includes a very quick and fair peer-review system, which is all easy to use. Visit http://www.dovepress.com/testimonials.php to read real quotes from published authors. 